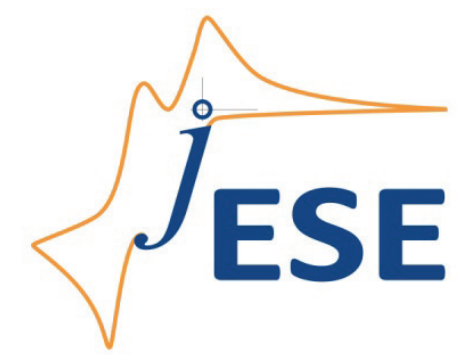

Open Access : : ISSN 1847-9286

www.jESE-online.org

Original scientific paper

\title{
Hardness and electrochemical behavior of ceramic coatings on Inconel
}

\author{
C. SUJAYA ${ }^{\llbracket}$, H. D. SHASHIKALA, G. UMESH, A. C. HEGDE*
}

Department of Physics, National Institute of Technology Karnataka, Surathkal, Srinivasnagar 575025, Karnataka, India

* Department of Chemistry, National Institute of Technology Karnataka, Surathkal, Srinivasnagar 575025, Karnataka, India

${ }^{\square}$ Corresponding Author: E-mail: sujayachendel@gmail.com; Tel.: +91 8242474000 ext 3278; Fax: +91 824 2474033

Received: April 18, 2011; Revised: October 13, 2011; Published: March 22, 2012

\begin{abstract}
Thin films of ceramic materials like alumina and silicon carbide are deposited on Inconel substrate by pulsed laser deposition technique using Q-switched Nd: YAG laser. Deposited films are characterized using UV-visible spectrophotometry and X-ray diffraction. Composite microhardness of ceramic coated Inconel system is measured using Knoop indenter and its film hardness is separated using a mathematical model based on area-law of mixture. It is then compared with values obtained using nanoindentation method. Film hardness of the ceramic coating is found to be high compared to the substrates. Corrosion behavior of substrates after ceramic coating is studied in $3.5 \% \mathrm{NaCl}$ solution by potentiodynamic polarization and electrochemical impedance spectroscopy measurements. The Nyquist and the Bode plots obtained from the EIS data are fitted by appropriate equivalent circuits. The pore resistance, the charge transfer resistance, the coating capacitance and the double layer capacitance of the coatings are obtained from the equivalent circuit. Experimental results show an increase in corrosion resistance of Inconel after ceramic coating. Alumina coated Inconel showed higher corrosion resistance than silicon carbide coated Inconel. After the corrosion testing, the surface topography of the uncoated and the coated systems are examined by scanning electron microscopy.
\end{abstract}

\section{Keywords}

Microhardness; Alumina; Silicon carbide; Pulsed laser deposition; Potentiodynamic polarization; Electrochemical impedance spectroscopy. 


\section{Introduction}

Nickel-base superalloy Inconel (NiCrFe alloy) is commonly used in aircraft gas engines, rocket engines, nuclear-power plants, petrochemical equipment and offshore industries [1,2]. In these applications, components must have reliable chemical and mechanical stability at high operating temperatures. Pitting corrosion of Inconel has also been reported [3] when used in components operating in corrosive medium. To overcome these problems, the surface of the alloy is usually coated with ceramic materials. Coatings of ceramic materials are especially suitable for the protection against wear and corrosion [4,5,6]. Alumina $\left(\mathrm{Al}_{2} \mathrm{O}_{3}\right)$ and silicon carbide $(\mathrm{SiC})$ are the ceramic materials widely used for surface coatings. These coatings can be produced by many chemical and physical vapor deposition techniques. One of them, Pulsed Laser Deposition (PLD), is considered as flexible, simple and easily controllable method for producing thin films [7]. Indentation microhardness is a reliable test method for the evaluation of the mechanical property of the coatings. The Knoop indenter is used for microhardness measurements. The Knoop indentation depth is shallower [approximately $1 / 30$ the long diagonal] than the Vickers indentation depth [approximately $1 / 7$ the average diagonal] when the same load is applied on the material. Hence, the Knoop indentation is better suited for testing of thin coatings. Hardness of thin films has combined effect of the substrate and the film that leads to the so-called "composite hardness". The composite hardness includes the component of the substrate hardness depending on the relative depth of penetration of the indenter and mechanical properties of both, the film and the substrate. Film hardness is separated from the composite hardness based on the area law of mixtures. Film hardness can also be determined by nanoindentation technique in which loaddisplacement curve is obtained by depth sensing indentation technique.

In the present study, efforts were made to get adhesive films of $\mathrm{Al}_{2} \mathrm{O}_{3}$ and $\mathrm{SiC}$ using PLD technique on the fine polished Inconel substrate at $450^{\circ} \mathrm{C}$. Usually thicker ceramic films are deposited at temperatures higher than $600^{\circ} \mathrm{C}$. In the present investigation adhesive films of lesser thickness (about $0.5 \mu \mathrm{m}$ ) were deposited at lower temperature $\left(450^{\circ} \mathrm{C}\right.$ ) and appreciable increase in microhardness and corrosion resistance after coating was observed. Processing parameters, like laser fluence, substrate target distance, and substrate temperature during the deposition are standardized using multiple trials. Composite microhardness of $\mathrm{Al}_{2} \mathrm{O}_{3}$ and $\mathrm{SiC}$ coatings are measured using Knoop indenter. Its film hardness is separated using a model based on Johnson and Hogmark [8], after including the effect of indentation size effect (ISE) [9], and compared with the values obtained using nanoindentation technique. A corrosion behavior of the coated substrate is studied in $3.5 \% \mathrm{NaCl}$ solution by potentiodynamic polarization and Electrochemical Impedance Spectroscopy (EIS) measurements.

\section{Experimental}

The substrate used is Inconel 601. The substrates are sequentially polished with $\mathrm{SiC}$ waterproof abrasive paper from 320 grit to 1500 grit size and with $\mathrm{Al}_{2} \mathrm{O}_{3}$ suspension of $1,0.5,0.3 \mu \mathrm{m}$ size to an average roughness $\left(R_{\mathrm{a}}\right)$ of $40 \mathrm{~nm}$. The polished surfaces are cleaned with acetone in ultrasonic bath for 20 minutes before the deposition of coating on the substrate.

A Q-switched Nd: YAG laser (Laser spectra) of wavelength $1064 \mathrm{~nm}$ and frequency $10 \mathrm{~Hz}$ was used for deposition. Laser beam of energy of $135 \mathrm{~mJ}$ focused to $0.1 \mathrm{~cm}$ diameter using a spherical lens of focal length $50 \mathrm{~cm}$ was impinged onto the rotating $\mathrm{Al}_{2} \mathrm{O}_{3}$ target. Inconel substrates of size $2 \times 2 \mathrm{~cm}^{2}$ were used for coating. Sintered $\mathrm{Al}_{2} \mathrm{O}_{3}$ and $\mathrm{SiC}$ pellets of thickness $0.4 \mathrm{~cm}$ and diameter $4 \mathrm{~cm}$ were used as targets. The rotation speed of 40 rotations per minute was used 
to avoid the crater formation. The incident angle between laser beam and target surface was kept at $45^{\circ}$. To obtain a uniform film thickness, the substrate was placed at $8 \mathrm{~cm}$ distance from the target surface.

The ablation was carried out in vacuum under the pressure of $10^{-3} \mathrm{~Pa}$, and at a substrate temperature of $450^{\circ} \mathrm{C}$. Figure 1 shows the schematic representation of the PLD system used in the present study.

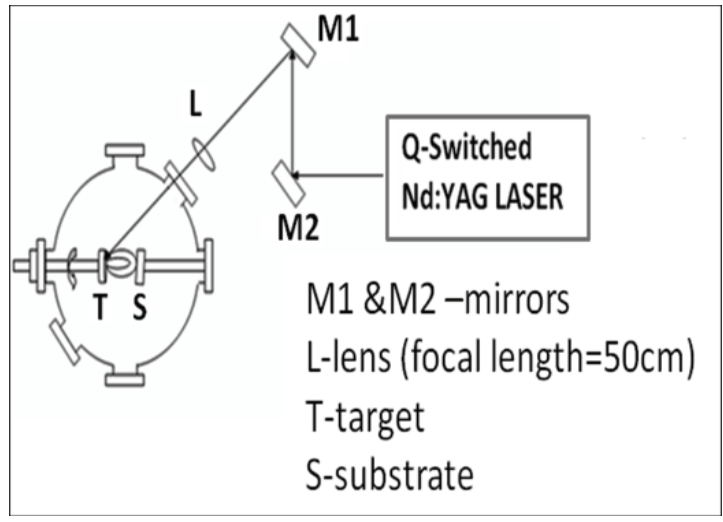

Figure 1. Schematic representation of the PLD system.

\section{Measurement techniques}

The average surface roughness was measured using 3-D optical surface profilometer (Vecco). Stylus profilometer (Taylor Hubson) was used to measure the film thickness. Optical absorption measurements were performed on $\mathrm{Al}_{2} \mathrm{O}_{3}$ and $\mathrm{SiC}$ coated glass substrate at room temperature using UV-Visible spectrophotometer (Ocean optics). XRD analysis (JEOL) was carried out by utilizing $\mathrm{CuK}_{\alpha}$ radiation on ceramic coated substrates.

Microhardness tester (Clemex) with Knoop indenter was used to measure the composite hardness. Loads of 25, 50, 100, 200, 300 and 500 g were employed at a dwell time of 10 seconds. At each load 10-12 indentations were made on the sample surface. The average microhardness at each load was calculated.

In the Knoop hardness measurement, the Knoop hardness is obtained from the following relation

$$
H K=14229 \frac{P}{L^{2}}
$$

where $H K$ is Knoop hardness in GPa, 14229 is a constant dependent on the indenter geometry. $P$ is the applied load in $N, L$ is the length of long diagonal of the resultant rhombic impression in $\mu \mathrm{m}$.

The microhardness measurement of the coating is the composite hardness of the film-substrate composite system. To separate the composite hardness into its constituents, a model based on area i.e., area "law-of mixture" approach is used. It was originally proposed by Jonsson and Hogmark [8] for Vickers indentation and later it is adapted to the geometrical configuration of the Knoop indenter [10]. The composite hardness, $H_{c}$ of the film-substrate system is expressed as

$$
H_{\mathrm{c}}=\frac{A_{\mathrm{f}}}{A} H_{\mathrm{f}}+\frac{A_{\mathrm{s}}}{A} H_{\mathrm{s}}
$$


where $A$ is the contact area; $H$ is the hardness; the subscripts $c, f$ and $s$ are related to the composite, film and the substrate, respectively and $A=A_{\mathrm{f}}+A_{\mathrm{s}}$. By means of simple geometrical relations depending on the Knoop indentation, equation for $A_{f} / A$ can be written as

$$
\frac{A_{\mathrm{f}}}{A}=\frac{2 c t}{L}-\frac{c^{2} t^{2}}{L^{2}}
$$

where $L$ is the length of the large diagonal, $t$ is the thickness of the film, $c=2.908$ for brittle film on the soft surface or $c=5.538$ for soft film on the soft surface [11]. Usually, measured hardness varies with load due to ISE which has not been taken into account in Jonsson and Hogmark model. Jonsson and Hogmark model is improved by incorporating the ISE taking into account a linear relation between hardness and the reciprocal indentation depth [12]. To obtain the true hardness of the film, the hardness variation with the applied load is written as

$$
\begin{aligned}
& H_{\mathrm{f}}=H_{\mathrm{fo}}+\frac{B_{\mathrm{f}}}{L} \\
& H_{s}=H_{\mathrm{so}}+\frac{B_{\mathrm{s}}}{L}
\end{aligned}
$$

where $H_{\mathrm{fo}}$ and $H_{\mathrm{so}}$ are the absolute hardness of the film and the substrate respectively, $B_{\mathrm{f}}$ and $B_{\mathrm{s}}$ are constants and $L$ is the indentation diagonal length. Substituting equation (3), (4) and (5) in (2) and neglecting second order $1 / L$ terms, the composite hardness becomes

$$
H_{\mathrm{c}}=H_{\mathrm{so}}+\frac{B_{\mathrm{c}}}{L}
$$

where $B_{\mathrm{c}}=B_{\mathrm{s}}+2_{\mathrm{ct}}\left(H_{\mathrm{fo}}-H_{\mathrm{so}}\right)$. To evaluate $H_{\mathrm{so}}$ and $B_{\mathrm{s}}$ values, hardness measurements on substrate was performed. The experimental plot $H_{s}$ versus $1 / L$ is approximated well by a linear regression. From the intercept and slopes of these plots, $H_{\mathrm{so}}$ and $B_{\mathrm{s}}$ of Inconel are obtained as $3.6 \mathrm{GPa}$ and $37.98 \mathrm{GPa} \mathrm{m}^{-1}$, respectively. The experimental data on the composite hardness of the filmsubstrate system, $H_{\mathrm{c}}$ is plotted against $1 / L$ and the intrinsic hardness of the film $\left(H_{\mathrm{fo}}\right)$ was calculated from the slope of the regression line using equation (6). Film hardness obtained from the above model was compared with the film hardness obtained using nano-indentation method.

Generally, it is not possible to measure the properties of a thin film independent of the substrate, using conventional testing equipment, unless coating is very thick. To determine the film hardness, the indentation depth should be $10 \%$ of the film thickness. In such cases nanoindenter was used. Common feature of this method is that it continuously monitors the load and the displacement as the indentation is produced. The feature of a continuous depth and load recording allows thin film properties to be obtained directly from the data without the need to measure indentation diagonals. The data were analyzed with the Oliver and Pharr method [13]. Hysitron Tribo indenter was used for the nanoindentation.

The corrosion behavior of the coated and uncoated substrates were studied using Tafel polarization studies by immersing samples in $3.5 \% \mathrm{NaCl}$ solution in open air and at room temperature, using potentiostat/galvanostat from Gamry Instruments (PCl 4G750-47065). All electrochemical measurements were performed using conventional three electrode cell, using a platinum plate as an auxiliary electrode, saturated calomel electrode (SCE) as a reference electrode. The exposed area working electrode to the corrosive medium was $1 \mathrm{~cm}^{2}$. The sample was cleaned in distilled water before loading it to the sample holder. The sample was placed in such a way that Luggin 
capillary of the reference electrode was close to the working electrode and this arrangement was used for all the tests. The open circuit potential $\left(E_{\text {ocp }}\right)$ or the steady state potential is maintained to study the potentiodynamic polarization. After achieving the stable $E_{\text {ocp }}$, the upper and the lower potential limits of the linear potential sweep were set at $\pm 250 \mathrm{mV} v s E_{\text {ocp }}$. The sweep rate was $1 \mathrm{mV} \mathrm{s}{ }^{-1}$. The Tafel plot was drawn using the obtained electrochemical data. The corrosion potential $\left(E_{\text {corr }}\right)$ and the corrosion current density $\left(i_{\text {corr }}\right)$ are deduced from the Tafel plot ( $\log / v s . E$ plot). The corrosion current density is obtained using the Stern-Geary equation [14]:

$$
i_{\text {corr }}=\frac{B}{R_{\mathrm{p}}}
$$

where $B=b_{\mathrm{a}} b_{\mathrm{c}} / 2.303\left(b_{\mathrm{a}}+b_{\mathrm{c}}\right)$ and where $B$ is called Stern-Geary constant, $b_{\mathrm{a}}$ and $b_{\mathrm{c}}$ are Tafel slopes for the anodic and cathodic reactions respectively and $R_{\mathrm{p}}$ is the polarization resistance expressed in $\Omega \mathrm{cm}^{2}$. The corrosion rate (CR) in micrometer per year $(y)$ was calculated from the Faraday's law [15] using the following equation

$$
C R=\frac{3.27 i_{\text {corr }} E W}{d}
$$

where $E W$ is the equivalent weight of the testing material in grams and $d$ is the density of the testing sample in $\mathrm{g} \mathrm{cm}^{-3}$. By substituting the value of $i_{\text {corr }}, C R$ was calculated.

Impedance measurements were conducted using the frequency response analyzer (FRA). The spectrum was recorded in the frequency range $10 \mathrm{mHz}-300 \mathrm{kHz}$. The applied alternating potential had the amplitude of $10 \mathrm{mV}$. After each experiment, the impedance data were displayed as Nyquist and Bode plots. A circuit description code (CDC) is assigned for the acquired data and the acquired data are curve fitted and analyzed using ZSimpWin software.

\section{Results and Discussion}

\section{Optical characterization of the coatings}

Adhesive coatings of $\mathrm{Al}_{2} \mathrm{O}_{3}$ and $\mathrm{SiC}$ were obtained on Inconel substrate by using the standardized parameters described in the previous section. The optical band gap energy and Urbach energy calculations for $\mathrm{SiC}$ and $\mathrm{Al}_{2} \mathrm{O}_{3}$ coated on the glass substrate were carried out using optical absorption data. The Tauc's plot is used to obtain the optical band gap energy $\left(E_{\mathrm{g}}\right)[16]$ :

$$
\alpha h v=\operatorname{const}\left(h v-E_{g}\right)^{p}
$$

where $E_{\mathrm{g}}$ is the optical band gap energy and $h v$ is the photon energy of the incident radiation, the exponent $p$ in the equation is 2 for the indirect optical transition and $p=1 / 2$ for the direct optical transition. The energy band gap $E_{\mathrm{g}}$ of $\mathrm{SiC}$ and $\mathrm{Al}_{2} \mathrm{O}_{3}$ film is obtained by extrapolating linear region of the curve obtained by plotting $(\alpha h v)^{1 / 2}$ as a function of $h v$ in the case of SiC (indirect band gap) and $(\alpha h v)^{2}$ versus $h v$ in the case of $\mathrm{Al}_{2} \mathrm{O}_{3}$ (direct band gap) as shown in Figures 2 and 3 . The $E_{\mathrm{g}}$ values are found to be $3.32 \mathrm{eV}$ for $\mathrm{Al}_{2} \mathrm{O}_{3}$ and $2.07 \mathrm{eV}$ for SiC film. These values match with the reported values of $3.2 \mathrm{eV}$ for $\mathrm{Al}_{2} \mathrm{O}_{3}$ [17] and 2-2.9 eV for SiC [18]. Generally, amorphous films have low band gap energies compared to crystalline films. 


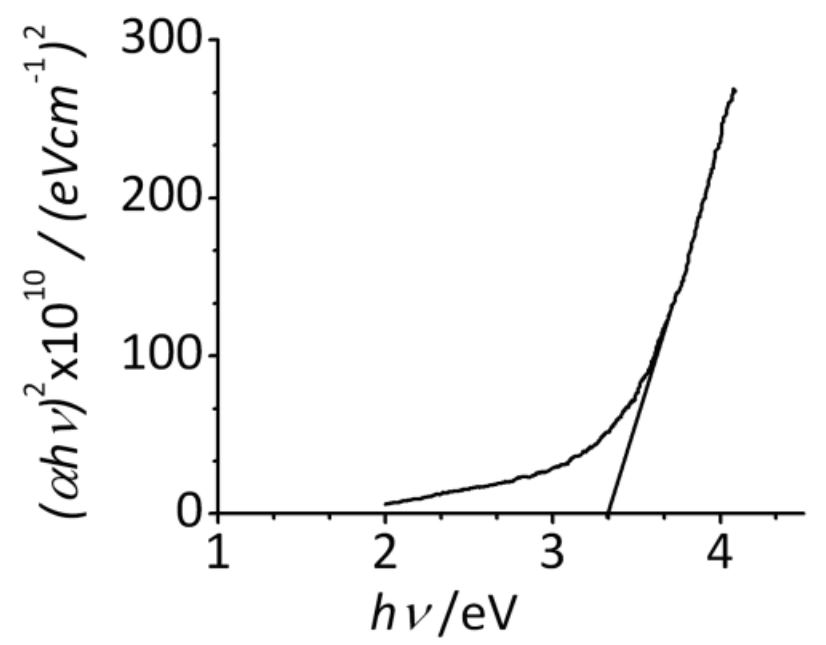

Figure 2. Absorption coefficient versus energy for the $\mathrm{Al}_{2} \mathrm{O}_{3}$ film.

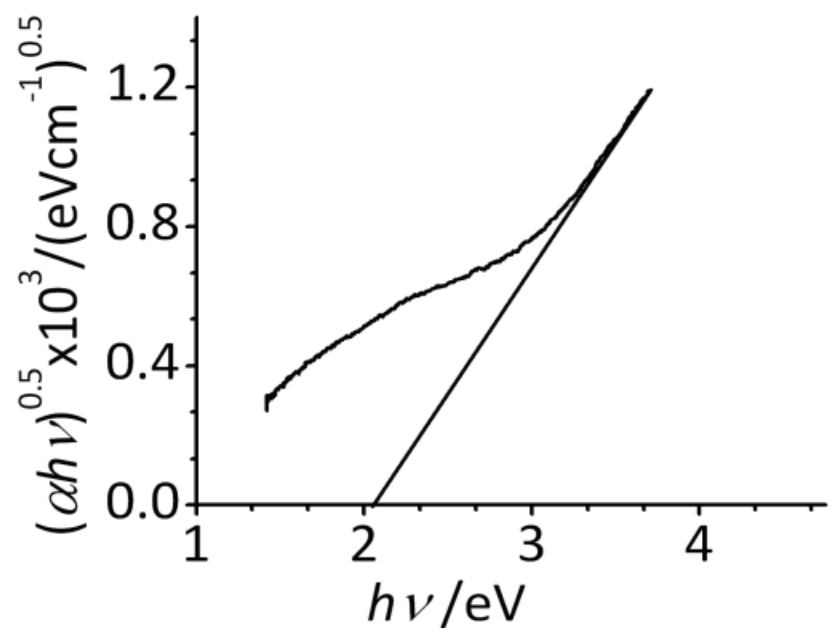

Figure 3. Absorption coefficient versus energy for the SiC film.

The obtained coated films are amorphous in nature. This was confirmed by optical absorption data. At longer wavelength in the spectrum, there is an absorption tail described by Urbach exponential law [19], which describes the amorphous nature of the film. The Urbach energy is related to the absorption coefficient as

$$
\alpha h v=\alpha_{\mathrm{o}} \mathrm{e}^{\frac{h v}{E_{u}}}
$$

where $\alpha_{\mathrm{o}}$ is a constant. The Urbach energy $E_{\mathrm{u}}$ is the measure of a disorder in the system.

Figures 4 and 5 correspond to the plot of $\ln \alpha$ as a function of $h v$. The value of Urbach energy was calculated by fitting the linear region of Figures 4 and 5 applying the method of least squares to the straight line equation ( $\ln \alpha=h v / E_{\mathrm{u}}+$ constant) and was found to be $1.49 \mathrm{eV}$ for $\mathrm{Al}_{2} \mathrm{O}_{3}$ and $1.39 \mathrm{eV}$ for $\mathrm{SiC}$ and film. Urbach energy $E_{\mathrm{u}}$ is the measure of structural disorder in the system. The value of Urbach energy obtained for $\mathrm{SiC}$ and $\mathrm{Al}_{2} \mathrm{O}_{3}$ confirms that the obtained films are amorphous in nature, which is confirmed also by the absence of sharp XRD peaks. 


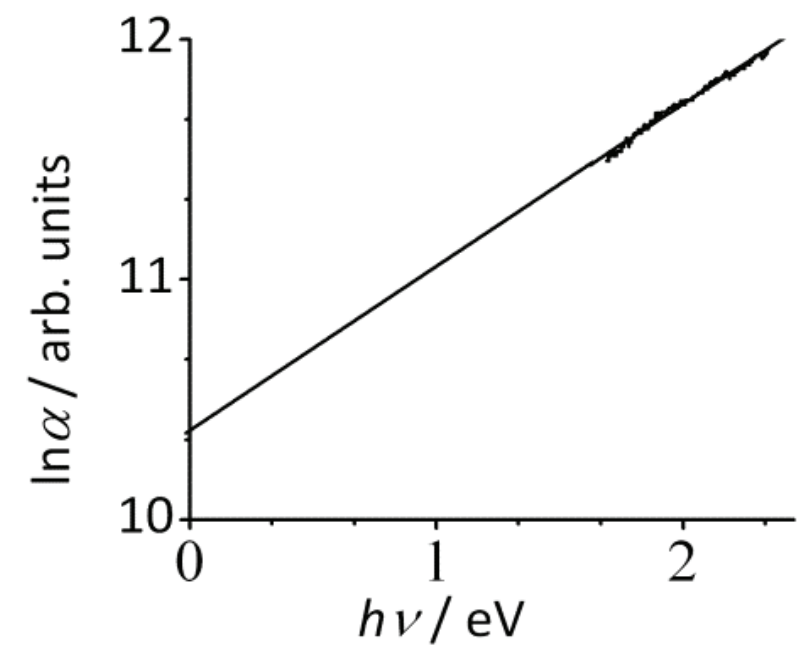

Figure 4. In $\alpha$ as a function of energy (hv) for $\mathrm{Al}_{2} \mathrm{O}_{3}$ film.

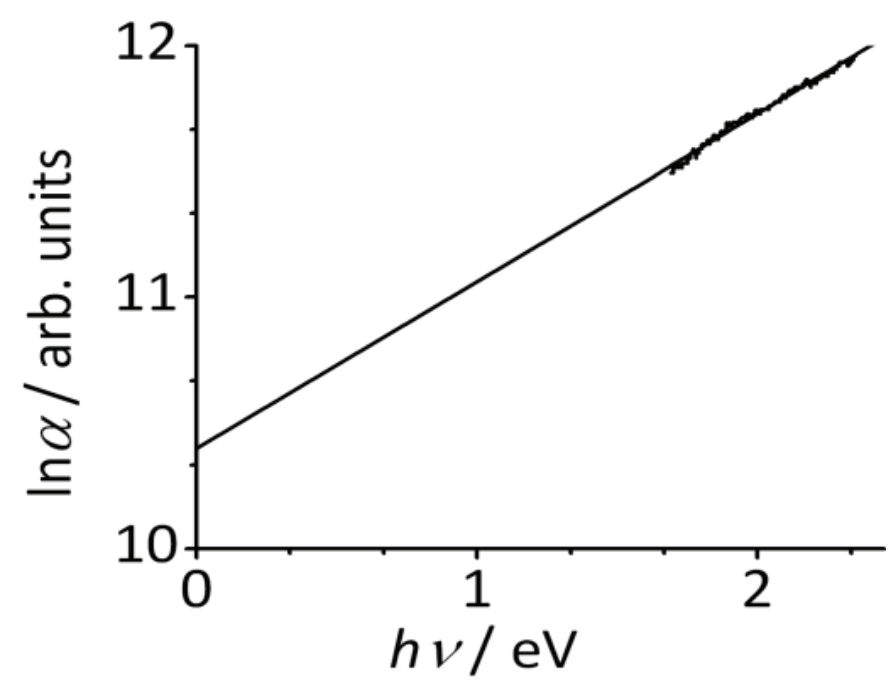

Figure 5. In a as a function of energy (hv) for SiC film.

\section{Hardness measurements}

Figures $6 \mathrm{a}$ and $6 \mathrm{~b}$ show the dependence of the measured composite film-substrate hardness on the inverse of indentation diagonal for $\mathrm{Al}_{2} \mathrm{O}_{3}$ and $\mathrm{SiC}$ coatings on Inconel. A least-square fit to the plots of the equation 6 results in the slope $B_{c}=\left[B_{s}+2 c t\left(H_{f o}-H_{s o}\right)\right]$. The value of $c$ is chosen depending on the film whether it is brittle or soft, since the nature of the films depends on their bulk material. Its value is 2.908 for brittle film and 5.538 for soft film $[11,20]$. To verify whether the film is brittle or soft we observed the nature of indentation on the surface of the coating. If the film is brittle it accommodates the indenter by crack formation. If it is a soft film, it plastically deforms to match the shape of the indenter. In the present study, there was no cracking of the film observed in $\mathrm{Al}_{2} \mathrm{O}_{3}$ and $\mathrm{SiC}$ deposited substrates even at high load (10 N) which is shown in Figure 7. A soft nature of the film is due to the amorphous structure of the coated film [21,22]. Since the deposition was carried out at low temperature $\left(450{ }^{\circ} \mathrm{C}\right)$, deposited ceramic films were not transformed into crystalline form as confirmed by optical absorption and XRD data.

From the above reasoning, assuming the film to be soft, the $c$ value is selected as $c=5.538$. Using the value of $B_{\mathrm{s}}$ and $H_{\mathrm{so}}$ of substrate, the intrinsic hardness of the films was calculated using 
the equation 6 . The slope of the straight line obtained by plotting $H_{c}$ versus $1 / L$ (Figure 6 ) was used to calculate the intrinsic film hardness $H_{\mathrm{fo}}$. The intrinsic hardness of the coated films is listed in Table 1. The film hardness gives of higher value than that of the substrate.

Nano-indentation measurements were performed on the surfaces of both, uncoated Inconel and with $\mathrm{Al}_{2} \mathrm{O}_{3}$ and $\mathrm{SiC}$, coatings in order to determine the hardness of coating. Figure 8 compares the indentation load-depth curve for Inconel substrate and $\mathrm{Al}_{2} \mathrm{O}_{3}$ film and $\mathrm{SiC}$ film of thickness 0.5 $\mu \mathrm{m}$ on Inconel. The indentation is carried out at the peak load of $1000 \mu \mathrm{N}$. The difference in hardness of the two samples is clearly evident from the difference in the depth obtained at the maximum load. The uncoated sample exhibits a larger indentation depth at the maximum load. In order to find the intrinsic hardness of the coated film an indentation depth should be 0.1 of the film thickness. The load was selected in such a way that its indentation depth was less than $0.05 \mu \mathrm{m}$ on the coated substrate. Table 2 compares the hardness value obtained using mathematical model, and the nano-indentation method and it shows that the two values are in a good agreement.
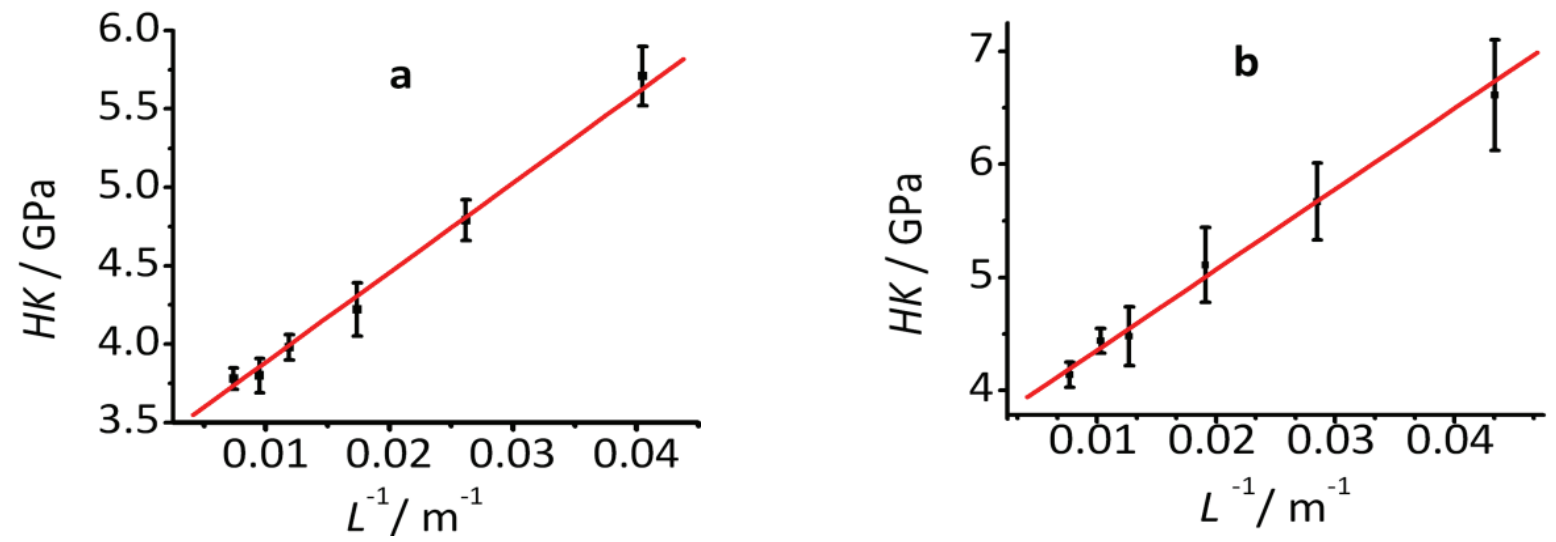

Figure 6. Knoop hardness variation with $1 / \mathrm{L}$ on a) $\mathrm{Al}_{2} \mathrm{O}_{3}$ and b) SiC coated film on Inconel.
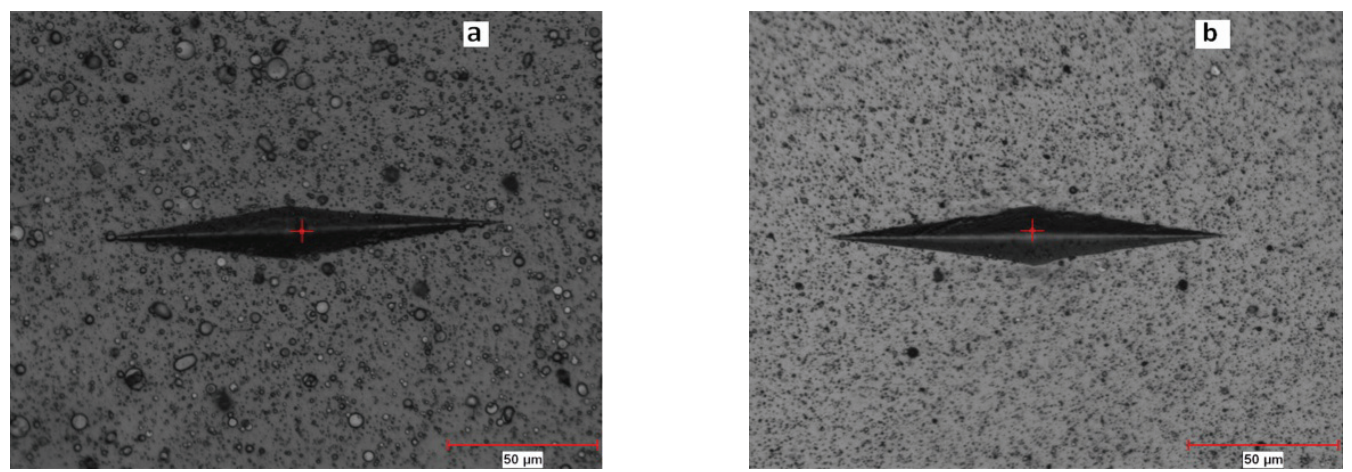

Figure 7. Knoop indentation on a) $\mathrm{Al}_{2} \mathrm{O}_{3}$ b) SiC coated film on Inconel substrate at $10 \mathrm{~N}$ load.

Table 1. Hardness data of coatings on Inconel

\begin{tabular}{|c|c|c|c|c|c|c|}
\hline Coating material & $t / \mu \mathrm{m}$ & $B_{\mathrm{s}} / \mathrm{GPa} \mathrm{m}^{-1}$ & $B_{\mathrm{c}} / \mathrm{GPa} \mathrm{m}^{-1}$ & $2 c$ & $H_{\mathrm{so}} / \mathrm{GPa}$ & $H_{\mathrm{fo}} / \mathrm{GPa}$ \\
\hline $\mathrm{Al}_{2} \mathrm{O}_{3}$ & 0.5 & 37.98 & 56.90 & 11.076 & 3.61 & 7.0 \\
\hline $\mathrm{SiC}$ & 0.5 & 37.98 & 64.74 & 11.076 & 3.61 & 8.6 \\
\hline
\end{tabular}




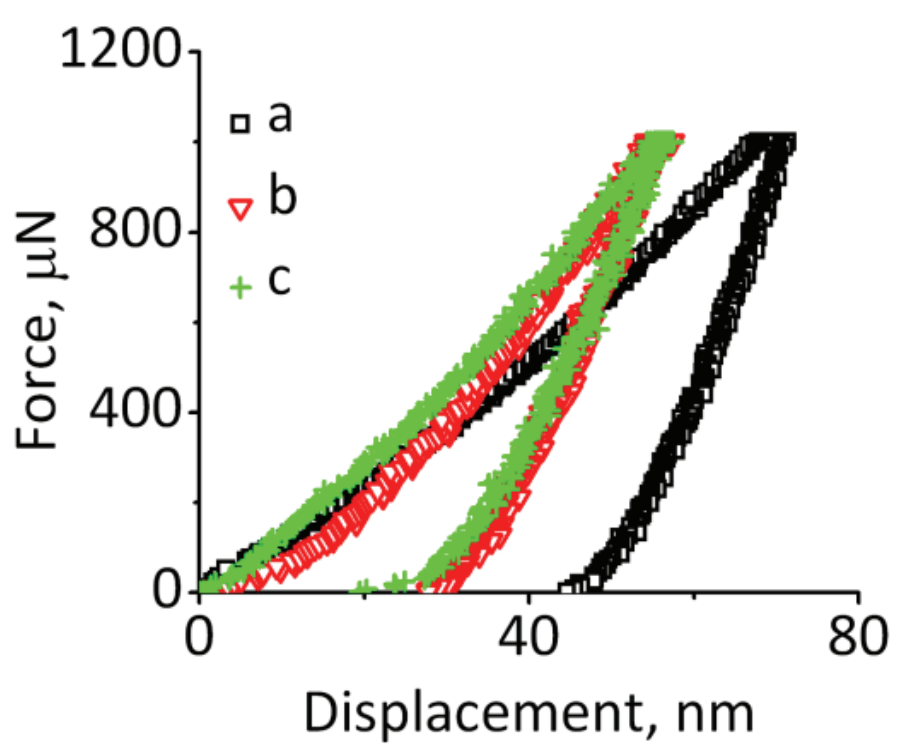

Figure 8. Load variations with nanoindentation depth a) substrate Inconel b) $\mathrm{Al}_{2} \mathrm{O}_{3}$ and c) $\mathrm{SiC}$ coating on Inconel.

Table 2. Comparison of hardness values obtained using a model and nanoindentation method.

\begin{tabular}{|c|c|c|c|c|}
\hline \multirow{2}{*}{ Material } & \multirow{2}{*}{$\begin{array}{l}\text { Surface } \\
\text { roughness, nm }\end{array}$} & \multirow{2}{*}{$\begin{array}{l}\text { Thickness } \\
\text { of the film, } \mu \mathrm{m}\end{array}$} & \multicolumn{2}{|c|}{ Hardness, GPa } \\
\hline & & & From Model & Nanoindentation \\
\hline $\mathrm{Al}_{2} \mathrm{O}_{3}$ on Inconel & 42.46 & 0.5 & 7.0 & 7.74 \\
\hline SiC on Inconel & 40.46 & 0.5 & 8.6 & 8.65 \\
\hline
\end{tabular}

\section{Potentiodynamic polarization measurements}

The Tafel plots obtained for Inconel, Inconel with $\mathrm{Al}_{2} \mathrm{O}_{3}$ and Inconel with $\mathrm{SiC}$ coatings of thickness $(t) 0.5 \mu \mathrm{m}$ in $3.5 \% \mathrm{NaCl}$ solution at $30{ }^{\circ} \mathrm{C}$ are shown in Figure 9 . The corrosion potential $\left(E_{\text {corr }}\right)$, the corrosion current density $\left(i_{\text {corr }}\right)$ and the corrosion rate are deduced from the Tafel (logi vs. E) plots. The values are listed in Table 3. For the Inconel substrate the $i_{\text {corr }}$ is approximately $1.007 \mathrm{nA} \mathrm{cm}^{-2}$ and it decreases to $0.235 \mathrm{nA} \mathrm{cm}^{-2}$ for alumina coatings and to $0.850 \mathrm{nA} \mathrm{cm}^{-2}$ for SiC coatings. Corrosion rate is directly proportional to $i_{\text {corr. }}$. It is established that $C R$ reduced drastically after ceramic coating. Alumina coated substrates exhibit excellent corrosion resistance. Corrosion rate after $\mathrm{Al}_{2} \mathrm{O}_{3}$ coating reduced to $1 / 4$ of that of Inconel, whereas $\mathrm{SiC}$ coated samples reduced to $1 / 2$ of Inconel. The improvement in the corrosion resistance of the substrate after ceramic coating is due to the fact that ceramic coating passivates the surface of the substrate and prevents the corrosion attack by electrolyte. Generally, in physical vapor deposited coatings, electrolytes enter into the substrate through the defects like pores and micro cracks and cause the corrosion of the substrate [23]. The protective coatings must fulfill the two main requirements to achieve the remarkable effect on corrosion resistance: a strong adhesion to the substrate and a low density of pores and cracks. The absence of pores and micro cracks completes surface coverage and good adhesion of the ceramic film coating to the substrate obtained by PLD technique enhances the corrosion resistance of the substrate. Enhanced corrosion rate of coatings on Inconel in the present study indicates that the coated films are having negligible concentration of pores and cracks. 


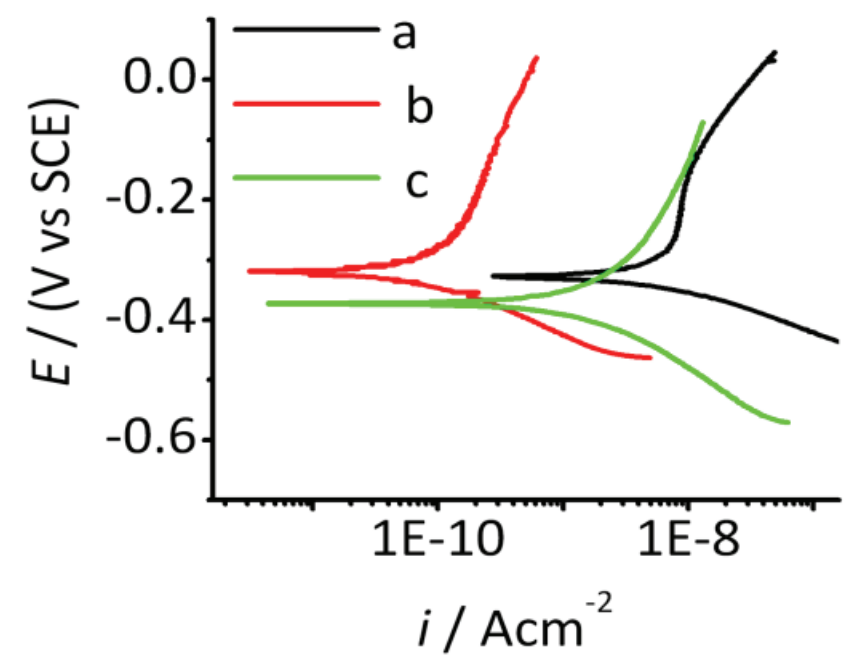

Figure 9. Potentiodynamic polarization curves of a) Inconel, b) $\mathrm{Al}_{2} \mathrm{O}_{3}$ coated Inconel and c) SiC coated Inconel.

Table 3. Potentiodynamic polarization measurements.

\begin{tabular}{|c|c|c|c|}
\hline & Inconel & $\mathrm{SiC}$ & $\mathrm{Al}_{2} \mathrm{O}_{3}$ \\
\hline$b_{\mathrm{a}} / \mathrm{mV} \mathrm{dec}^{-1}$ & 110.9 & 125.9 & 62.59 \\
\hline$b_{\mathrm{c}} / \mathrm{mV} \mathrm{dec}^{-1}$ & 44.9 & 78 & 165.5 \\
\hline$i_{\text {corr }} / \mathrm{nA} \mathrm{cm}^{-2}$ & 3.69 & 1.007 & 0.235 \\
\hline$E_{\text {corr }} / \mathrm{mV}$ & -328.0 & -372.0 & -321.0 \\
\hline$C R / \mu \mathrm{m}$ year $^{-1}$ & 44.00 & 29.95 & 12.78 \\
\hline$R_{\mathrm{p}} / \mathrm{M} \Omega \mathrm{cm}^{-2}$ & 3.76 & 20.8 & 83.9 \\
\hline
\end{tabular}

\section{Electrochemical impedance spectroscopy studies}

Figures 10, 11 and 12 show the impedance response of Inconel, Inconel with $\mathrm{Al}_{2} \mathrm{O}_{3}$ and Inconel with SiC coatings as Nyquist and Bode plots. The EIS data obtained from these plots are listed in Table 4. The Nyquist plots show unfinished semicircles what is attributed to the charge transfer controlled reactions [24]. Bode plots in the form of phase angle vs. log $\omega$ showed that the phase angles remain almost constant between higher and lower frequencies.
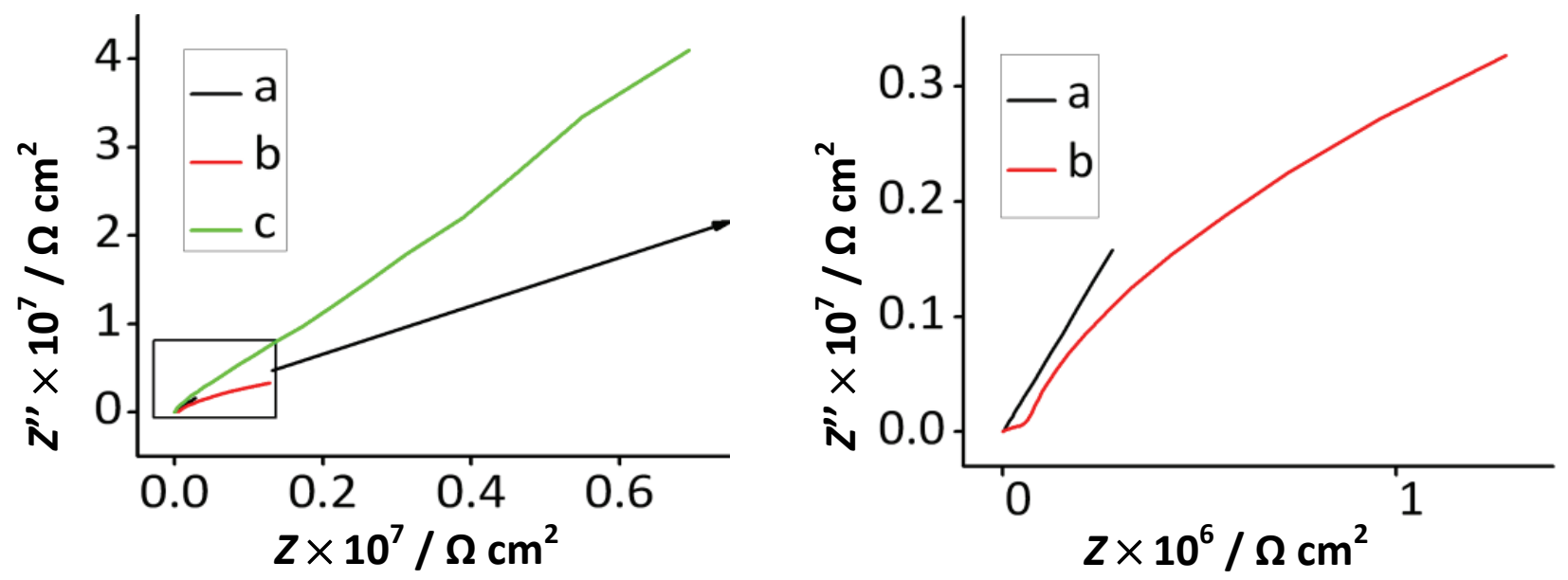

Figure 10. Nyquist plots of: a) Inconel, b) $\mathrm{SiC}$ and c) $\mathrm{Al}_{2} \mathrm{O}_{3}$ coatings. 


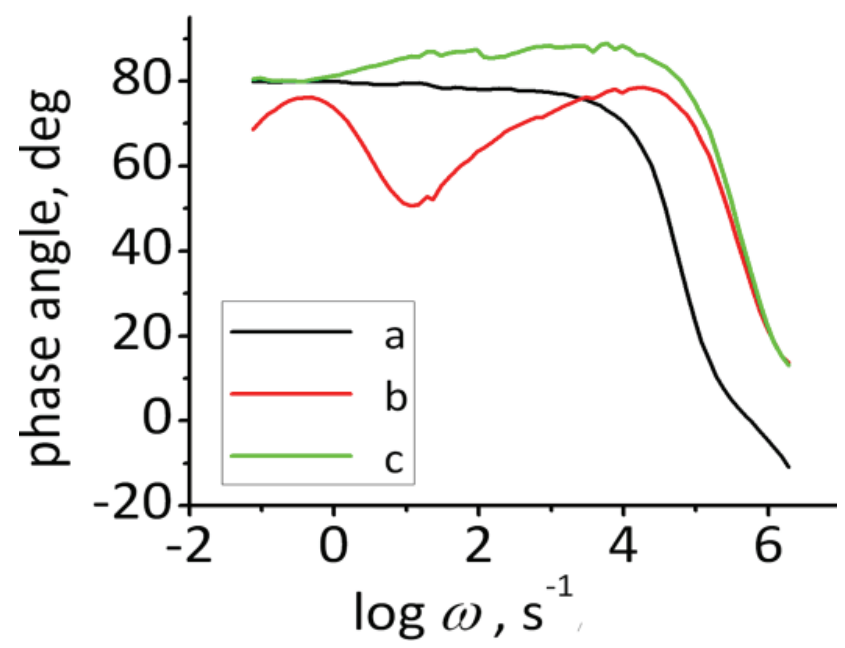

Figure 11. Bode plots (phase angle vs. log $\omega)$ of a) Inconel, b) $\mathrm{SiC}$ and c) $\mathrm{Al}_{2} \mathrm{O}_{3}$ coatings.

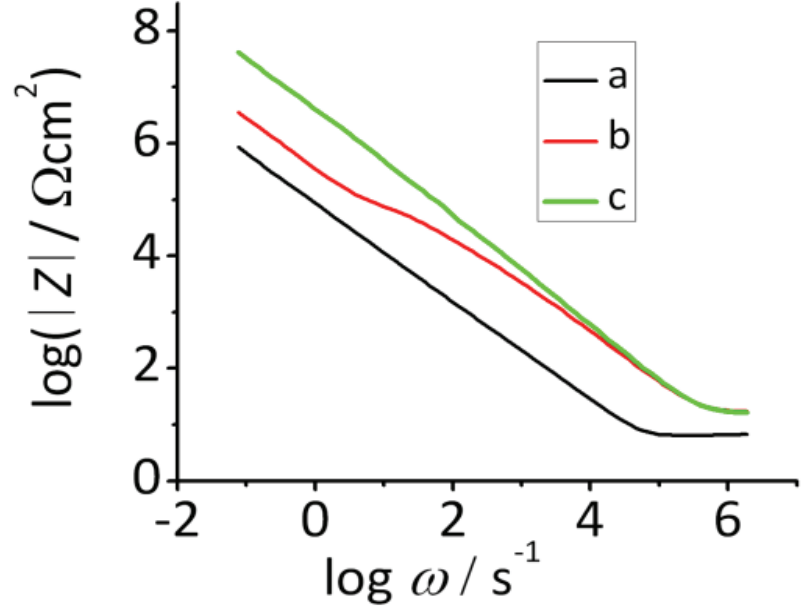

Figure 12. Bode plots (log/Z/vs. log $\omega)$ of a) Inconel, b) $\mathrm{SiC}$ and c) $\mathrm{Al}_{2} \mathrm{O}_{3}$ coatings.

The simplified equivalent circuits are shown in Figure 13. The values of solution resistance $\left(R_{\mathrm{s}}\right)$, charge-transfer resistance $\left(R_{\mathrm{ct}}\right)$, pore resistance $\left(R_{\mathrm{p}}\right)$, total capacitance $(Q)$ of the constant phase element (CPE) are listed in Table 4. The $R_{\mathrm{ct}}$ increases in the following order: Inconel substrate $<$ $<\mathrm{SiC}$ coated Inconel $<\mathrm{Al}_{2} \mathrm{O}_{3}$ coated Inconel, which shows that the alumina coated Inconel has the highest corrosion resistance. The values of $R_{\mathrm{ct}}$ are strongly dependent on the passive film characteristics and are an indication for corrosion of materials. This supports the results obtained using potentiodynamic polarization measurements. $\log |Z|$ vs. $\log \omega$ plots of Fig. 12 show that the absolute impedance increased in the same order as mentioned above. The equivalent circuit for Inconel is shown in Fig. 13(a). It consists of a double layer capacitance, which is parallel to the charge transfer resistance, both of which are in series with the solution resistance between the working electrode (WE) and the tip of the Luggin capillary. The double layer capacitance provides information about the polarity and the amount of charge at the substrate/electrolyte interface. For better quality of fitted results, pure capacitance is replaced with constant phase element (CPE) that accounts for deviation from ideal dielectric behavior. Its admittance, $Y=Z^{1}$, is defined as:

$$
Y(\omega)=Q(j \omega)^{n}
$$

where $Q$ is an adjustable parameter used in the non-linear least squares fitting and $n$ is also an adjustable parameter that always lies between 0.5 and 1 . The value of $n$ is obtained from the slope of $\log |Z|$ versus log $\omega$ plot (Figure 12 ). The phase angle $(\theta)$ can vary between $-90^{\circ}$ (for a perfect capacitor $(n=1)$ ) and 0 (for a perfect resistor $(n=0)$ ). The CDC for the equivalent circuit proposed for Inconel is $R(Q) R$. When the sample is immersed in the electrolyte, the defects in the coating provide the direct diffusion path for the corrosive media. In this process the galvanic corrosion cells are formed and the localized corrosion dominates the corrosion process. In such cases, electrochemical interface can be divided into two sub-interfaces: electrolyte/coating and electrolyte/substrate. The proposed equivalent circuit for such a system is shown in Figure 13(b). The parameters in the equivalent circuit $R_{\mathrm{p}}$ and $Q_{\mathrm{c}}$ are related to the properties of the coating and the electrolyte/coating interface reactions. $R_{\mathrm{ct}}$ and $Q_{\mathrm{dl}}$ are related to the charge-transfer reaction at the electrolyte/substrate interface. The CDC of the proposed equivalent circuit for the coated sample is $R(Q[R(Q R)])$. From the EIS data given in Table 4, it is evident that $Q_{c}$ decreased from SiC coating to alumina coating, indicating that $\mathrm{SiC}$ coatings contain relatively more pores and less dense microstructure as compared to alumina coatings. 


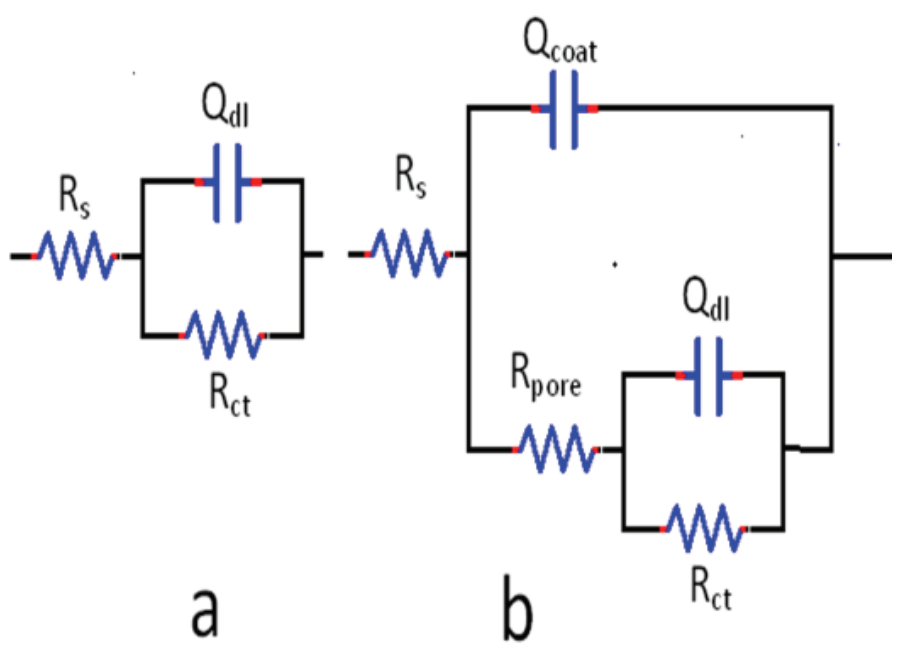

Figure 13. a) equivalent circuit to fit the electrochemical impedance data of the Inconel substrate and b) equivalent circuit to fit the electrochemical impedance data of the coated substrate.

\section{Scanning Electron Microscopy (SEM) Studies}

After the corrosion testing, the surface morphology of the uncoated and the coated system are studied by SEM. The corrosion pits were observed on the uncoated Inconel after the corrosion test (Figure 14a). Corrosion pits are not found in $\mathrm{Al}_{2} \mathrm{O}_{3}$ and $\mathrm{SiC}$ coated samples, (Figures 14b and 14c)). Pits are formed as a result of corrosion attack on the uncoated surface. The improvement in the corrosion resistance is due to adherent thin $\mathrm{Al}_{2} \mathrm{O}_{3}$ film coating deposited on the surface of the substrate which will not allow the direct contact of the electrolyte with the substrate. EDAX analysis indicates the presence of sodium $(\mathrm{Na})$ and chlorine $(\mathrm{Cl})$ in the regions where the pits are formed. Similar conclusion can be drawn in corrosion behavior of SiC coated Inconel.

Table 4. EIS data obtained by equivalent circuit simulation of $\mathrm{SiC}$ and $\mathrm{Al}_{2} \mathrm{O}_{3}$ coatings.

\begin{tabular}{cccccccc}
\hline Sample & $\begin{array}{c}\mathrm{R}_{\mathrm{s}} \\
\Omega \mathrm{cm}^{-2}\end{array}$ & $\begin{array}{c}Q_{\mathrm{dl}} \\
\Omega^{-1} \mathrm{~s}^{\mathrm{n}}\end{array}$ & $n_{\mathrm{dl}}$ & $\begin{array}{c}R_{\mathrm{ct}} \\
\mathrm{M} \Omega \mathrm{cm}^{-2}\end{array}$ & $\begin{array}{c}Q_{\text {coat }} \\
\Omega^{-1} \mathrm{~s}^{\mathrm{n}}\end{array}$ & $n_{\mathrm{c}}$ & $\begin{array}{c}R_{\text {pore }} \\
\mathrm{M} \Omega \mathrm{cm}^{-2}\end{array}$ \\
\hline Inconel & 15.46 & 2.07 & 0.8 & 0.89 & & & \\
\hline Inconel/SiC & 14.66 & 0.212 & 0.89 & 21.07 & 0.73 & 0.87 & 7.66 \\
\hline Inconel/Al $\mathrm{O}_{3}$ & 15.82 & 0.16 & 0.99 & 108 & 0.085 & 0.74 & 18.6 \\
\hline
\end{tabular}
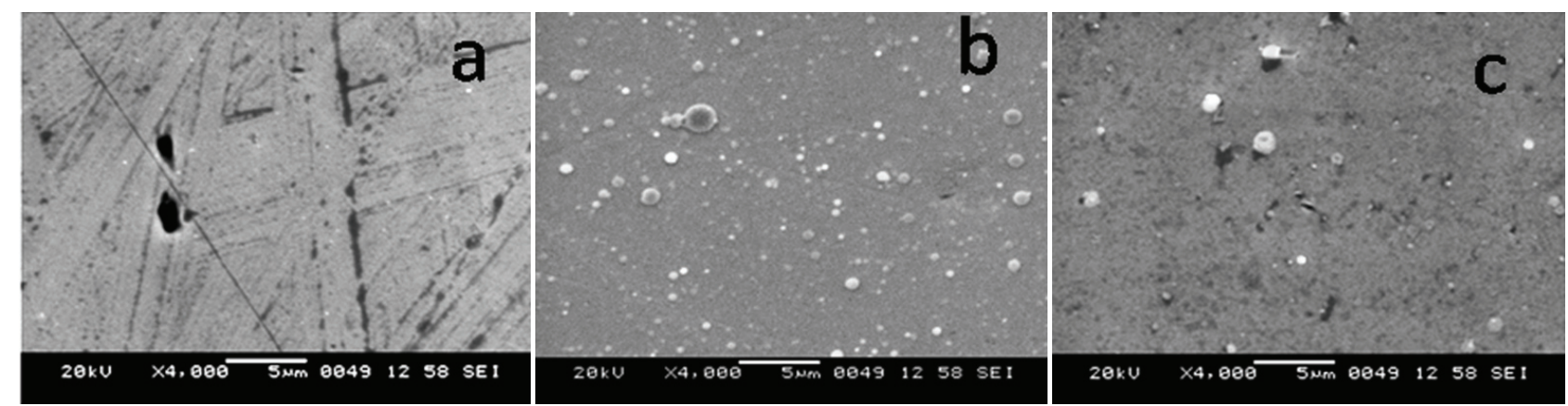

Figure 14. Surface morphology of the a) Inconel substrate b) alumina c) SiC coated substrate surface. 


\section{Conclusions}

Adhesive thin films of $\mathrm{Al}_{2} \mathrm{O}_{3}$ and $\mathrm{SiC}$ have been deposited on Inconel substrate by PLD technique using Nd: YAG laser of wavelength $1064 \mathrm{~nm}$. Knoop microhardness of the film-substrate system gives the composite microhardness. Film hardness can be separated from the composite hardness using a model based on area law of mixtures. It is nearly equal to the film hardness measured using nanoindentation technique. The potentiodynamic polarization and the EIS measurements showed that $\mathrm{Al}_{2} \mathrm{O}_{3}$ and $\mathrm{SiC}$ coatings exhibit better corrosion resistance as compared to that of substrate.

Acknowledgements: The authors would like to thank Indian Space Research Organization (ISRO) for financial assistance in carrying out this research and to Vikram Sarabhai Space Centre (VSSC), Trivandrum for supplying substrate materials.

\section{References}

[1] S.H. Jeong, C.W. Cho, Z. Lee, Tribol. Int. 38 (2005) 283-288

[2] C.J. Wang, S.M. Chen, Surf. Coat. Tech. 201 (2006) 3862-3866

[3] Y.I. Kim, H.S. Chung, W.W. Kim, J.S. Kim, W.J. Lee, Surf. Coat. Tech. 80 (1996) 113-116

[4] C. Cibert, H. Hidalgo, C. Champeaux, P. Tristant, C. Tixier, J. Desmaison, A. Catherinot, Thin Solid Films 516 (2008) 1290-1296

[5] M. Zaytouni, J.P. Rivière, Wear 197 (1996) 56-62

[6] Y. Li, J. Yao, Y. Liu, Surf. Coat. Tech. 172 (2003) 57-64

[7] T.J. Zhu, L. Lu, M. O. Lai, Appl. Phys. A 81(4) (2005) 701-714

[8] B. Jönsson, S. Hogmark, Thin Solid Films 114 (1984) 257-269

[9] G. Guillemot, A. lost, D. Chicot, Thin Solid Films 518 (2010) 2097-2101

[10] A. lost, Scripta Mater. 39 (1998) 231-238

[11] F. Torregrosa, L. Barrallier, L. Roux, Thin Solid Films 266 (1995) 245-253

[12] A. lost, R. Bigot, Surf. Coat. Tech. 80 (1996) 117-120

[13] W.C. Oliver, G.M. Pharr, J. Mater. Res. 7 (1992) 1564-1583

[14] V.S. Sastri, Corrosion Inhibitors-Principles and Applications, John Willy and Sons, Chichester, 1998.

[15] S.W. Dean, in Electrochemical Techniques for Corrosion, R. Baboian, Ed., National Association of Corrosion Engineers; Houston, TX, USA, 1977, p. 52-60

[16] J. Tauc, Optical Properties of Solids, F. Abels Ed., North-Holland, Amsterdam, 1972, p. 277

[17] V. Rose, V. Podgursky, I. Costina, R. Franchy, Surf. Sci. 541 (2003) 128-136

[18] Y.J. Park, Y.W. Park, J.S. Chun, Thin Solid Films 166 (1988) 367-374

[19] F. Urbatch, Phys. Rev. 92 (1953) 1324

[20] D. Ferro, S.M. Barinov, J.V. Rau, A. Latini, R. Scandurra, B. Brunetti, Surf. Coat.Tech. 200 (2006) 4701-4707

[21] J. Esteve, A. Lousa, E. Martinez, H. Huck, E.B. Halac, M. Reinoso, Diam. Relat. Mater.10 (2001) 1053-1057

[22] M. Sridharan, M. Sillassen, J. Bottiger , J. Chevallier , H. Birkedal, Surf. Coat. Techn. 202 (2007) 920-924

[23] H.C. Barshilia, K. Yogesh, K.S. Rajam, Vacuum 83 (2009) 427-434

[24] L. Liu, Y. Li, F. Wang, Electrochim.Acta 52 (2007) 7193-7202 